\title{
Modeling of Surface Drainage during the Service Life of Asphalt Pavements Showing Long-Term Rutting: A Modular Hydromechanical Approach
}

\author{
Stefan Alber ${ }^{D},{ }^{1}$ Barbara Schuck, ${ }^{1}$ Wolfram Ressel, ${ }^{1}$ Ronny Behnke $\left(\mathbb{D},{ }^{2}\right.$ \\ Gustavo Canon Falla, ${ }^{3}$ Michael Kaliske ${ }^{D},{ }^{2}$ Sabine Leischner, ${ }^{3}$ and Frohmut Wellner ${ }^{3}$ \\ ${ }^{1}$ Institute for Road and Transport Science, Universität Stuttgart, Faculty of Civil and Environmental Engineering, \\ 70569 Stuttgart, Germany \\ ${ }^{2}$ Institute of Structural Analysis, Technische Universität Dresden, Faculty of Civil Engineering, 01062 Dresden, Germany \\ ${ }^{3}$ Institute of Urban and Pavement Engineering, Technische Universität Dresden, Faculty of Civil Engineering, \\ 01062 Dresden, Germany \\ Correspondence should be addressed to Stefan Alber; stefan.alber@isv.uni-stuttgart.de
}

Received 7 April 2020; Revised 8 July 2020; Accepted 13 July 2020; Published 12 August 2020

Guest Editor: Meng Guo

Copyright (C) 2020 Stefan Alber et al. This is an open access article distributed under the Creative Commons Attribution License, which permits unrestricted use, distribution, and reproduction in any medium, provided the original work is properly cited.

\begin{abstract}
This paper presents a modular hydromechanical approach to assess the short- and long-term surface drainage behavior of arbitrarily deformable asphalt pavements. The modular approach consists of three steps. In the first step, the experimental characterization of the thermomechanical asphalt material behavior is performed. In the second step, information about the longterm material behavior of the asphalt mixtures is integrated on the structural scale via a finite element (FE) tire-pavement model for steady-state rolling conditions and time homogenization in order to achieve a computationally efficient long-term prediction of inelastic deformations of the pavement surface (rut formation). In the third step, information regarding the current pavement geometry (deformed pavement surface) is used to carry out a surface drainage analysis to predict, e.g., the thickness of the water film or the water depth in the pavement ruts as a function of several influencing quantities. For chosen numerical examples, the influence of road geometry (cross and longitudinal slope), road surface (mean texture depth and state of rut deformation), and rainfall properties (rain intensity and duration) on the pavement surface drainage capacity is assessed. These parameters are strongly interrelated, and general statements are not easy to find. Certain trends, however, have been identified and are discussed.
\end{abstract}

\section{Introduction}

The ultimate goal of pavement design is to provide an optimal structure that meets the required service life while ensuring safety and minimizing costs and environmental impacts.

One major problem is the rapid increase in the volume of traffic with growing axle loads, which leads to amplified fatigue mechanisms and the premature failure of pavement structures. A further effect is intensified rut formation [1]. Increased temperatures, due to global warming, exacerbate this effect [2]. Rutting is related to the long-term behavior of the pavement structure and describes the accumulation of permanent vertical deformations due to repeated traffic loading. Rutting is undesirable due to several reasons: (1) increased risk of water infiltration (through cracks) into the pavement structure with several deterioration effects, (2) higher fuel consumption as a result of a higher level of friction on the outside edge of the tire profile, and (3) accumulation of water (or even ice) constituting a potential traffic safety risk due to aquaplaning.

In this context, an increasing demand on design asphalt mixtures with a high resistance to permanent deformation at high temperatures is observable. To optimize the design of these materials, detailed analyses of the inelastic deformation are required. Hence, the results of laboratory tests can be used to determine the constitutive material relations 
between dynamic variables (i.e., stresses and forces) and kinematic quantities (i.e., strains and displacements). The most commonly used laboratory tests are the static creeprecovery test and the cyclic uniaxial compression (CUCT) test. Creep-relaxation tests are popular because of their simplicity. However, some authors have reported that the results do not correlate well with actual in-service pavement rutting [3]. The CUCT is, on the other hand, more compatible with in-field conditions, and the results are more consistent with in-service rutting measurements [4]. Since rutting is, in general, a long-term phenomenon, accelerated test procedures are important for the reduction of testing times [5].

By using the results of appropriate laboratory tests, numerical modeling techniques provide additional means for predicting the rutting behavior of asphalt pavements on the structural scale. These simulations employ material parameters which are obtained via the results of laboratory tests on the material scale. Material tests are also essential for the calibration and validation of any kind of numerical model in order to obtain realistic and reliable simulation results. Compared to the outcome of rutting tests on a laboratory scale, an advantage of modeling ruts (in combination with real tire models) is also that a more realistic geometrical form of the rut can be determined. Numerical models for rutting with different methodological approaches can be found in the literature (e.g., [1, 5-12]).

The combination of laboratory tests and numerical modeling is a promising way to make predictions regarding pavement rutting. The rut depth itself can be one of the results. However, further conclusions for the pavement performance can be drawn by coupling the results of the laboratory tests and the structural simulation with a model which deals with the surface drainage of the pavement.

Various methods to calculate or model pavement surface drainage exist in the literature. The still widely used Gallaway et al.'s equation was developed from empirical relationships and experimental data [13]. Based on calculations, road criteria are suggested to reduce the risk of hydroplaning. The equation can also be used to estimate the hydroplaning speed (the speed in which hydroplaning occurs) as a function of road and car tire characteristics. Anderson et al. [14] and Cristina and Sansalone [15] developed a $1 \mathrm{D}$ kinematic wave model of the surface runoff, while Hermann [16] calculated slope lines that predict the $1 \mathrm{D}$ flow lines of runoff caused by road geometry. These models cannot be used to calculate water film depth distributions, but runoff coefficients, drainage inlet designs, or an estimation of the drainage capacity of a roadway can be obtained. A more sophisticated model has been developed by Charbeneau et al. [17]. A diffusion wave model is used to numerically simulate $2 \mathrm{D}$ water depth distributions over the pavement surface. A study to evaluate the influence of longitudinal slope on the maximum water depth and its location is also included. While some of these models are applicable to complex road geometries and alignments, in-depth parameter studies are still needed to evaluate the complex mechanism of pavement surface runoff.
Furthermore, German guidelines use the simple value of rut depth (considering the specific cross slope situation as well) to describe the risk of aquaplaning. With a better knowledge of the surface drainage mechanism, this assessment could be improved. A 2D surface drainage model can provide additional information about the risk of critical water depths in the ruts leading to aquaplaning. Other important parameters, such as longitudinal slope and the geometrical form of the ruts-in interaction with the cross slope-can be integrated into the surface drainage model and improve information on the risk of aquaplaning in a specific case. Furthermore, it is possible to consider the effects of the surface texture in and next to the ruts or even their development over time. In this way, much more information about (future) surface drainage behavior can be determined than by merely using the value of rut depth to describe the risk of aquaplaning.

In this contribution, it is exemplarily shown that the experimental and numerical analysis of geometrical changes (deformations in the form of ruts) of arbitrary asphalt pavements can be combined and coupled with an analysis of functional properties addressing road users' needs regarding safety and comfort. Therefore, a modular hydromechanical approach consisting of three steps (experimental material testing, long-term structural deformation finite element (FE) modeling, and surface drainage modeling) is proposed. This approach is also one of the first steps towards a more comprehensive, future vision of long-term pavement performance and its prediction with the help of in situ monitoring, data collection, data management, and modeling techniques-often called a "digital twin" in the context of industrial products or processes.

\section{Modular Hydromechanical Approach}

The present approach consists of several unidirectionally coupled modules (material, structure, and drainage) to describe the long-term behavior of arbitrary asphalt pavements from the material scale to the structural scale and to derive the surface drainage features over the long term. A graphical overview of the methodologies is provided in Figure 1.

The flowchart of the modular analysis is depicted in Figure 2. A modular hydromechanical analysis starts with the selection and experimental testing of different materials used for the specific pavement design. From material databases or additional experimental characterization tests, model parameters are derived, which are used in the subsequent numerical analysis to describe the thermomechanical material behavior of the pavement materials on the structural scale via adequate models. To realistically capture the phenomena of tire-pavement interaction within the structural model, a representative rolling tire in steadystate motion and parts of the pavement construction are discretized and included in the numerical model. Via a longterm simulation of the selected tire-pavement configuration, geometrical information regarding the permanent deformation of the pavement surface is obtained. The geometrical data is used as input for the numerical surface drainage 


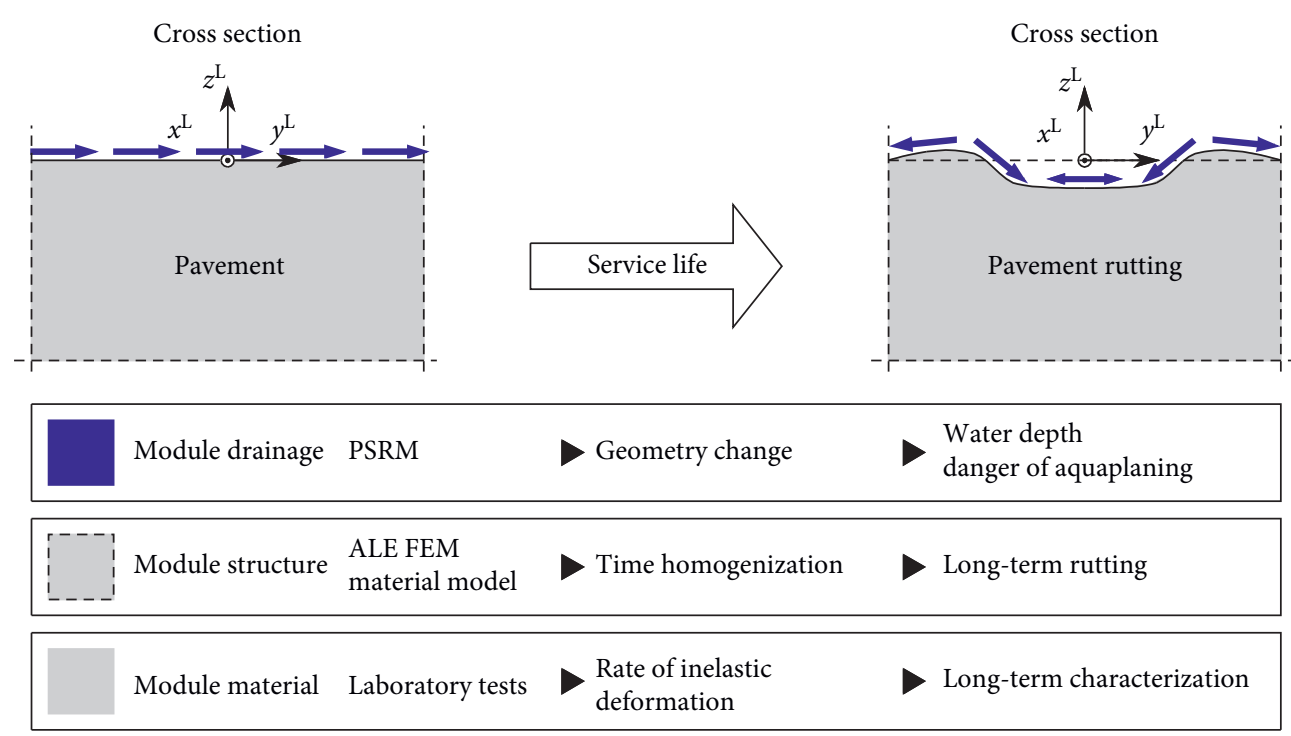

Figure 1: Overview of the modular unidirectional hydromechanical investigation for deformable asphalt pavements subjected to rut formation during their service life: pavement surface runoff model (PSRM) and arbitrary Lagrangian-Eulerian finite element method (ALE FEM).

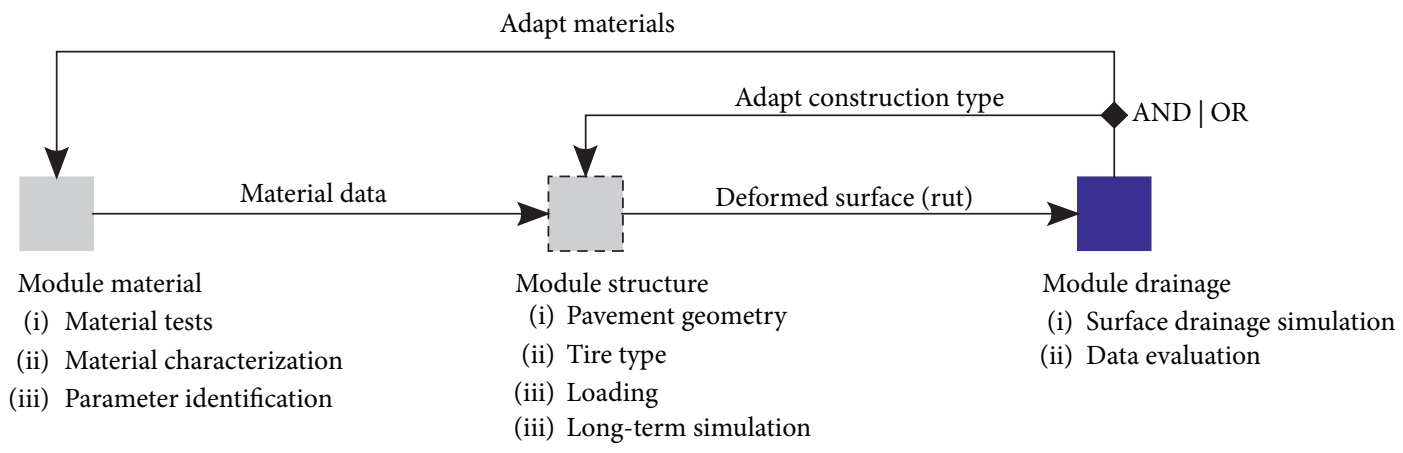

FIgURE 2: Flowchart of the modular analysis.

analysis. As a result of the unidirectionally coupled holistic analysis, pavement materials or the construction type of the pavement can be varied to optimize the short- and long-term drainage features (loop).

In the following subsections, more information on each module is provided, with a focus on the geometry-dependent model for surface drainage in this contribution.

2.1. Material Characterization. The objective of the experimental material characterization is to reveal the material's short- and long-term response to cyclic loading. Particularly for the prediction of plastic deformations, the quantification of accumulated inelastic deformations is important. The existence of different testing facilities and the general need of a test methodology for accurate inelastic strain measurements during the experimental testing of asphalt materials have already been briefly discussed in the introduction. To assess the thermomechanical material behavior of asphalt mixtures, i.e., to also take into account the influence of temperature, the short- and long-term tests are performed at different testing temperatures. The outcome of these force- controlled tests (strain-time plots) is then used to identify sets of material model parameters for each testing temperature. Besides the temperature-dependent mechanical response of the material, other thermal characteristic values such as heat capacity, thermal conductivity, and mass density also have to be identified from experiments. These additional quantities are used as the input parameters of the thermomechanical tire-pavement model (see $[2,18])$.

2.2. Tire-Pavement Model for the Long-Term Prediction of Permanent Surface Deformation. The experimentally assessed asphalt behavior is numerically represented via a continuum mechanical model for asphalt [19] with several sets of model parameters to capture the asphalt's temperature dependency. While the material response to shortterm loading (e.g., tire overrun) only shows deformations in the small strain range, long-term deformations (accumulation of inelastic deformation sections) show large deviations from the pavement's initial geometry. Hence, a material model considering large strains was employed. Furthermore, a continuum mechanical material model 
formulation-see, e.g., [20-22] for an overview-is chosen to enable a numerically efficient representation of the shortand long-term behavior of asphalt materials on the macroscale within numerical simulations in the framework of the finite element method (FEM). Within the material model, the evolution of inelastic deformations is described via an endochronic plasticity approach [23]. A detailed derivation and explanation of the approach is available in [24].

The temperature dependency of the asphalt is captured via parametrization via sets of model parameters identified for discrete testing temperatures (see Section 2.1). Furthermore, the thermal properties of the asphalt mixture are described with the thermal conductivity and the volumetric heat capacity, which are assumed as constant (temperatureand deformation-independent) in the material model.

To integrate and evaluate the short- and long-term material response on the structural scale (pavement structure), different numerical methods are available. Often, the FEM is used to carry out numerical simulations of pavement structures (see, e.g., $[19,25])$. As a further development with respect to numerical efficiency, the semianalytical finite element method (SAFEM) has recently been proposed in [26].

In this contribution, an FE discretized configuration of tire and pavement is considered (see Figure 3). A detailed description of the tire-pavement model for the long-term prediction of pavement rutting is available in [27]. In the following, a brief overview of the underlying theory and assumptions is provided.

For a numerically efficient but still detailed analysis of the tire-pavement interaction, a stationary state of the tire in motion is numerically represented with the help of an ALE steady-state transport simulation. The idea of the steadystate analysis is based on the special description and decomposition of the motion of the tire and the pavement with respect to several configurations (initial configuration with Lagrangian frame $x^{\mathrm{L}}$, moving reference configuration fixed to the tire axle with coordinate systems $x^{\prime}$ and $x^{\mathrm{ALE}}$, and current configuration).

Due to the steady-state motion of tire and pavement, time derivatives (of quantities belonging to the current configuration) with respect to the moving reference configuration are redundant and the computational cost can be significantly decreased. In this context, the rotation of the tire is represented by the flow of the tire material through the fixed FE mesh of the tire, and no fine FE resolution of the whole circumferential direction of the tire is required (see Figure 3). The translation is represented in the same manner by a flow of the pavement material through the FE mesh of the pavement. Inelastic material behavior (e.g., viscoelastic or elastoplastic material features) is included in the FE analysis for both tire and pavement via a special ALE formulation for inelastic material (evaluation of the history of the material along streamlines formed by consecutive integration points of the regular FE mesh) (see $[2,18]$ ). In the tire-pavement model, longitudinal and cross slopes of the pavement are omitted since their influence on the rut formation is

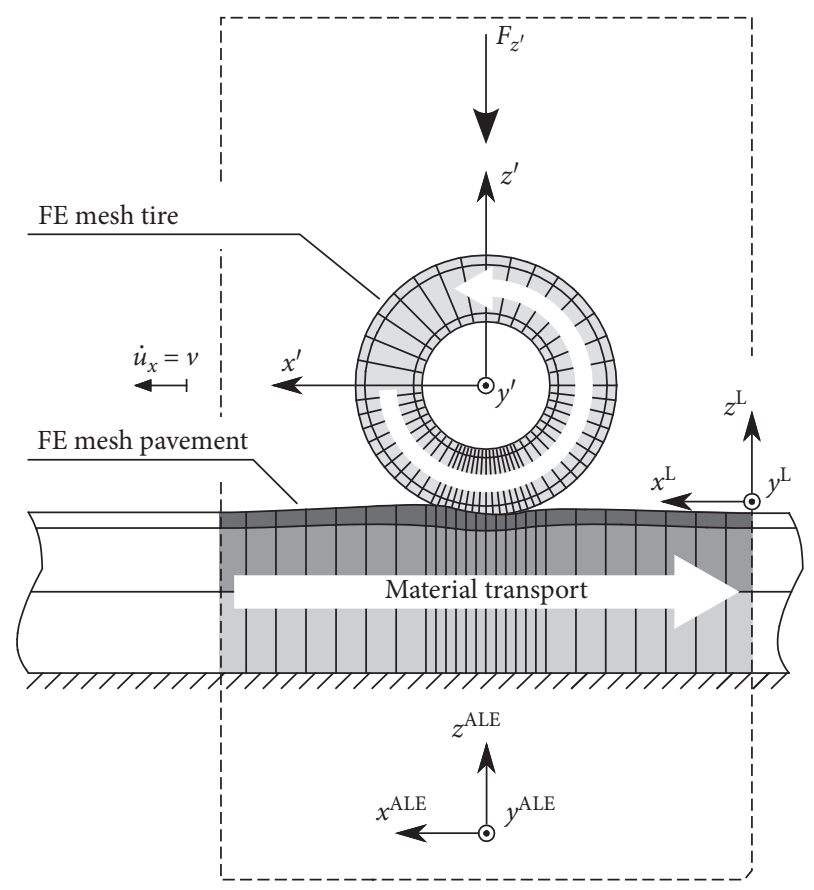

FIGURE 3: FE tire-pavement model for the structural analysis of the tire-pavement interaction using an ALE framework for both tire and pavement.

judged as negligible for standard sections of the road network.

The long-term prediction of the pavement's rutting performance requires the use of a numerically efficient strategy. In this context, time homogenization-see, e.g., [28-33] - on several time scales has been used for the multifield problem (displacement and temperature as solution fields) as proposed in [27]. From the mechanical loading (tire overrun [34]) and boundary conditions (temperature variations), distinct time scales have been identified for which a time-homogenized response of the pavement structure is computed and evaluated with respect to a reference cross section of the pavement.

Information regarding the geometry of the deformed pavement surface (cross-sectional direction) as a function of the number of load cycles (tire overruns) are then transferred to the surface drainage analysis.

2.3. Geometry-Dependent Model for Surface Drainage. In the past, models for the surface drainage of pavements have often been developed solely from experimental data and were not based on physical modeling. Descriptive parameters or equations were derived from experimental results to gain a reduced model of pavement drainage, as in [35-37]. In some of these cases, the experiments have been explained by simplified analytical approaches [38-40], e.g., based on the Gauckler-Manning-Strickler equation, which is commonly used in hydromechanics for the calculation of flow conditions in open channels. Another often-used simplification is the assumption of $1 \mathrm{D}$ flow $[16,40,41]$.

In this contribution, a $2 \mathrm{D}$ numerical model called the Pavement Surface Runoff Model (PSRM), developed at the 
University of Stuttgart [42], is used to calculate the water depth, depending on the evolving surface geometry described in Section 2.2. While experimental data is used to calibrate some coefficients, the equations are based on a physical model of surface flow.

The PSRM was designed to model pavement surface runoff and can, therefore, only simulate infiltration processes into porous pavements in a simplified way. A number of models dealing with flow and drainage in porous pavements have previously been proposed (e.g., $[43,44])$. Porous pavement drainage is also addressed in the authors' DFG Research Group FOR 2089 [45] (see, e.g., [46, 47]).

The numerical calculations of the PSRM, which are based on fundamental hydromechanical modeling, use the $\mathrm{DuMu}^{\mathrm{X}}$ software toolbox $[48,49]$. This toolbox was developed to solve different flow problems by using the DUNE framework $[50,51]$. DUNE itself is a C++ toolbox for solution approaches for differential equations, also beyond hydromechanical flow modeling.

In the PSRM, standard geometries (e.g., superelevated transition sections with different cross slopes and longitudinal slopes or different pavement widths) can be generated for ideal even surfaces. More realistic and complex (uneven) topographies and geometries of pavement surfaces can be imported using 3D surface data. This data can either be measured or-as done in the present modular hydromechanical investigation-calculated based on a structural tire-pavement model (Section 2.2) so that even complex geometries (e.g., intersections or ruts) can be taken into account. Furthermore, the roughness of the pavement surface can be considered in the PSRM as mean texture depth (MTD), which has a major influence on water reservoirs in the texture and on the flow resistance in many cases. Five different surface textures with discrete MTD values between 0.4 and $1.8 \mathrm{~mm}$ can be used as input parameters for the PSRM simulations.

In the PSRM, rainfall is simplified to a spatially uniform event, which is constant in time, as it is also implemented in a simplified way in other (pavement) drainage models. Furthermore, the rainfall intensity $i(\mathrm{~mm} / \mathrm{min})$ constitutes another input parameter.

\subsubsection{Mathematical Description of the Pavement Runoff} Model. The Navier-Stokes equations are a set of fundamental equations concerning fluid mechanics and characterize the conservation of mass, momentum, and energy in hydrosystems with a set of nonlinear partial differential equations.

If water is treated as an incompressible fluid and its motion as a temperature-independent flow, the conservation of energy can be neglected. For laminar flow conditions in combination with an ideal frictionless fluid and vertically acting gravity, the so-called incompressible Euler equations can be derived from the Navier-Stokes equations.
It is assumed that laminar flow is the only drawback of the PSRM compared to surface drainage situations in reality. In measurements, water flow has been observed in the full range between laminar and fully turbulent conditions (see $[17,41])$. However, in [41], it was concluded that fully turbulent flow will only occur in unusually strong rainfall events. Based on this outcome, it seems reasonable to assume laminar flow and, hence, to further simplify the mathematical formulation.

In pavement surface runoff, the horizontal spread of the water film is much larger than the water depth. For cases like these, the depth-averaged shallow water equations are ideal [42]. They state that, in shallow free-surface problems, the vertical flow velocity and its derivatives are very small (hydrostatic pressure distribution) and can, therefore, be neglected.

Integrating the incompressible Euler equations over the flow depth, the depth-averaged shallow water equations in their general form are obtained for a simplified model of the pavement surface (see Figure 4):

$$
\frac{\partial}{\partial t}\left(\begin{array}{c}
h \\
u h \\
v h
\end{array}\right)+\frac{\partial}{\partial x}\left(\begin{array}{c}
u h \\
u^{2} h+\frac{1}{2} g h^{2} \\
u v h
\end{array}\right)+\frac{\partial}{\partial y}\left(\begin{array}{c}
v h \\
u v h \\
v^{2} h+\frac{1}{2} g h^{2}
\end{array}\right)=\left(\begin{array}{c}
0 \\
g h S_{0, x} \\
g h S_{0, y}
\end{array}\right) .
$$

So far, (1) is only applicable to a smooth surface. The right-hand side of the equation represents the source and sink terms of the flow problem. The surface slope $S_{0}$ in the $x$ and $y$-direction acts as a source, since the gravity $g$ acts on the momentum of the fluid.

The equation has to be further adapted for the modeling of pavement surface runoff. In surface drainage, the discharge $q$ can be a source or a sink term in the system since water can be added (e.g., rain) or it can be removed from the system (e.g., discharge at pavement gutters and inlets, evaporation, and infiltration). Hence, the discharge has to be included as a source term in the shallow water equations.

Furthermore, assuming a smooth pavement surface is not practical. Flow resistance has a large effect on flow velocities. In free flow cases, the roughness of the surface acts as shear stress against the gravitational force and decelerates the flow [42]. Therefore, higher surface roughness does not necessarily lead to an improvement of the drainage function of the road. Formulating the influence of flow resistance is particularly difficult. Even if slope friction is only considered in terms of bottom resistance with resistance of shape, wave, flow fluctuations, wind and rain neglected, the flow resistance would still have to be calculated via direct numerical simulation (DNS) (see [42]). For this reason, an empirical equation for the flow resistance was used. After a theoretical comparison, the Darcy-Weisbach equation was chosen for the PSRM (rather than the equations by Chézy or 


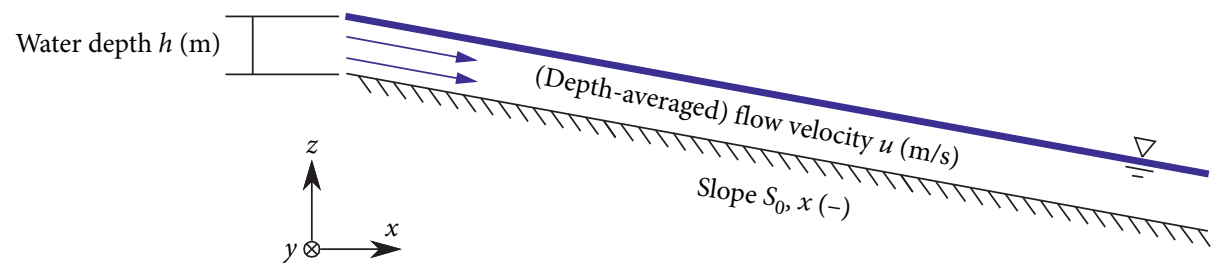

Figure 4: Model of water flow with velocity $u$ over a pavement surface in the $x$-direction. The flow velocity $v$ in the $y$-direction can be modeled analogously.

Manning) [42]. Darcy-Weisbach uses the dimensionless coefficient $f$ as an empirical value, derived from a theoretical background. This formulation has the advantage that it can be applied to all flow regimes (laminar, transient, and turbulent).

Assuming a steady state, an expression for the slope friction $S_{f}$ (caused by the base friction of the rough pavement surface) can be derived from the Darcy-Weisbach theories in the $x$ - and $y$-direction:

$$
\begin{aligned}
& S_{f, x}=f \frac{u \sqrt{u^{2}+v^{2}}}{8 g h}, \\
& S_{f, y}=f \frac{v \sqrt{u^{2}+v^{2}}}{8 g h} .
\end{aligned}
$$

For this case, the Darcy-Weisbach coefficient $f\left(F r_{k}, \lambda, S_{0}\right)$ depends on the texture-related Froude number $F r_{k}$, the inundation ratio $\lambda$, and the bottom slope $S_{0}$ [42]. The texture-related Froude number $F r_{k}$, in turn, is defined in the derivation of these equations as the Froude number with mean texture depth MTD as the characteristic length:

$$
F r_{k}=\frac{u}{\sqrt{g \mathrm{MTD}}}
$$

Equation (3) provides $F r_{k}$ in the $x$-direction with the corresponding flow velocity $u$. For the $y$-direction, the texture-related Froude number can be computed via the flow velocity $v$.

The inundation ratio $\lambda$, as a describing parameter of the Darcy-Weisbach coefficient $f$, is defined as the relationship of the water depth to the characteristic length of the rough surface, i.e. the water depth compared to the height of the pavement texture. The influencing parameters are investigated and compared to experimental data from [16]. It seems that the texture-related Froude number has a larger influence on $f$ than the inundation ratio [42]. Furthermore, the data indicates that inserting the inundation ratio into the definition of the Darcy-Weisbach coefficient does not increase the accuracy [42]. For this reason, $\lambda$ as a variable of the coefficient $f$ is dropped. The influence of the bottom slope $S_{0}$ on the Darcy-Weisbach coefficient is investigated via a curve fitting process [42] and is found to have a significant influence on $f$ and, therefore, is kept as a secondary parameter.

The coefficient $f$ itself is then derived empirically. Experimental findings $[16,41]$ are used to obtain the parameters of the following relation:

$$
f=a_{1} S_{0}^{a_{2}} \mathrm{Fr}_{k}^{a_{3}}
$$

The free parameters are identified via the least squares method [42]:

$$
f=3.50 S_{0}^{0.47} F r_{k}^{-1.50} \text {. }
$$

The experiments $[16,41]$ employed to calibrate the PSRM for pavement roughness/texture are carried out on five different realistic pavement surfaces. As described in [41], the test equipment consists of $2.5 \mathrm{~m} \times 1.0 \mathrm{~m}$ samples $\left(2.5 \mathrm{~m}^{2}\right)$ of three different asphalt types (SMA 11, SMA 8, and a mastic asphalt) and two concrete surfaces obtained by different texturing methods. The variation of MTD is between $0.4 \mathrm{~mm}$ and $1.8 \mathrm{~mm}$. The flow conditions in the experiments can be assumed as $1 \mathrm{D}$ (no cross slope), with a flow path length of $2.5 \mathrm{~m}$. An inflow construction at the top of the pavement sample ensures steady-state flow conditions. In the experiments, a variation of longitudinal slopes and runoff rates (simulating different rain intensities at certain flow path lengths) are tested. Water film thicknesses are measured using an ultrasonic device, which measures distances on the dry surfaces and on the surfaces with water flow, respectively. The measured difference between the distances, repeated at 27 fixed points on the surface, results in an average water depth. The experiments are described in more detail in $[16,41,47]$.

More experimental data might improve the accuracy and applicability of the model. Although the model is only valid and applicable for five discrete values of MTD, these are, in fact, within a sufficiently wide range compared to realistic pavements.

Including the discharge $q$ as a source, as described above, and the slope friction $S_{f}$ in the $x$ - and $y$-direction in (1), the depth-averaged shallow water equations applicable to pavement surface runoff are obtained via [42]:

$$
\frac{\partial}{\partial t}\left(\begin{array}{c}
h \\
u h \\
v h
\end{array}\right)+\frac{\partial}{\partial x}\left(\begin{array}{c}
u h \\
u^{2} h+\frac{1}{2} g h^{2} \\
u v h
\end{array}\right)+\frac{\partial}{\partial y}\left(\begin{array}{c}
v h \\
u v h \\
v^{2} h+\frac{1}{2} g h^{2}
\end{array}\right)=\left(\begin{array}{c}
q \\
g h S_{0, x}-g h S_{f, x} \\
g h S_{0, y}-g h S_{f, y}
\end{array}\right) .
$$

\subsubsection{Numerical Approach of the Pavement Runoff Model.} The PSRM uses the finite volume method (FVM) on a Cartesian grid to gain numerical solutions to the previously derived shallow water equations. A $2 \mathrm{D}$ grid is used and the conserved variables are stored as cell-averaged values at the center of each cell. The pavement is implemented as an impervious boundary, and no-flow conditions are imposed on the right and left sides of the model domain. 
The numerical approach was implemented in $\operatorname{DuMu}^{\mathrm{X}}$ (as explained in Section 2.3); see [47] for a more detailed description and [42] for the complete derivation of the mathematical equations and the numerical approach.

\section{Numerical Examples of the Hydromechanical Approach}

Most drainage models for porous (e.g., [43, 44, 52]) or nonporous (e.g., [14-16]) asphalt materials mainly focus on the determination of critical water depths and the choice of design parameters for adequate and safe drainage conditions (e.g., required cross slope, adequate longitudinal slope, thickness of porous friction course, and spacing of subdrains). In addition, many modeling approaches and predictions of water depths for certain pavement geometries often consider simplified ideally even surfaces, which, in terms of pavements, do not exist in reality.

In the following, the surface drainage model (Section 2.3 ) is coupled to the material description (Section 2.1) and the structural tire-pavement model (Section 2.2) to show the influence of deformation (e.g., rutting) on the pavement's drainage performance. The objective of the considered examples is to show how changing pavement surface geometries effects drainage and, therefore, if the drainage functions of the pavement are also fulfilled in the long term (during the service life of the pavement). If these life-cycle approaches for pavement drainage properties are based on basic material and structural modeling, substantial improvements of such analyses can be expected.

To demonstrate the fundamental features of the hydromechanical approach, the simple but illustrative example of a tire running on an artificial test section (thin asphalt layer on deformable subbase material), as sketched in Figure 5, is considered. Systematic analyses, e.g., for varying parameters of the material, pavement construction types, traffic, wheel loads, pavement slopes, and several further parameters, are beyond the scope of this contribution. The geometry, thermomechanical boundary conditions, and material features of the benchmark example are provided in detail in [27]. The geometry and material data of the tire are available in [34]. The tire is subjected to a vertical load of $F_{z^{\prime}}=3300 \mathrm{~N}$ and a steadystate translational velocity of $80 \mathrm{~km} / \mathrm{h}$ in the $x$-direction. Regarding the input parameters and assumptions used for this example, it should be noted that this is not representative of highly loaded real pavements. The main objective of this study is to show the method itself and its possibilities and not (yet) to analyze more realistic pavement structures and tire loads.

As a result of the structural analysis, the permanent surface deformation (given in Figure 6) of the test section is used as a starting point for the surface drainage analysis.

Information regarding the permanent surface deformation (2D) of a representative part of the cross section subjected to rut formation is used to generate a $3 \mathrm{D}$ geometrical model of the road surface, including the longitudinal and cross slopes via inter- and extrapolation of the geometrical data. Figure 7 shows a virtual pavement surface.
To achieve this result, the following steps are carried out. As can be seen in Figure 6, the rut-related deformations force the road material to the sides of the rut beyond the normal level. It is assumed that this bulge on the outer side of each rut decreases linearly to the normal level in $0.3 \mathrm{~m}$ (see Figure 7(b)). This rut geometry is then doubled at a distance of $1.5 \mathrm{~m}$ (equal to one track width) and thus forms the crosssectional geometry of a lane with a width of $3.5 \mathrm{~m}$. The cross sections are then extrapolated for different longitudinal and cross slopes over a length of $10 \mathrm{~m}$. A local minimum of the pavement surface exists in the middle of the track (see Figure $7(\mathrm{~b})$ ). This is due to the raised edges of the ruts and has an influence on the surface drainage. The pavement surface runoff model (PSRM) used for the surface drainage analysis could be utilized for even larger road sections (e.g., several lanes) or a more complex alignment of the road (e.g., curves or transition zones). The grid for the numerical modeling is calculated in PSRM based on these 3D geometrical models of the road surface. This allows a $2 \mathrm{D}$ calculation of the water depths in all surface directions. The grid size and, therefore, the resolution for the numerical calculations are $0.05 \mathrm{~m}$ in the following examples.

For the numerical examples of surface drainage, a variation of rain intensities $i$, rainfall durations, and texture depths (MTD) have been simulated. The longitudinal slopes $s$, cross slopes $c$, and the simulated time span of rut formation $n$ from the tire-pavement simulation (Section 2.2) are also part of the investigated examples.

The chosen rain intensities represent (short) heavy rainfall events (e.g., "showers" during a thunderstorm) as they usually appear in Germany. The intensities of heavy rainfall events vary widely within Germany. Therefore, the determination of an "average" value for a certain duration of heavy rainfall events has a great uncertainty; the rain intensities which are chosen in the following examples have been varied accordingly. Statistical analyses of rain intensities in Germany [53] have been considered in order to choose adequate rain intensities. For further applications of the model, any other rain intensities and durations can be simulated as well.

Table 1 provides the selected input values for the following drainage examples. One influencing quantity of pavement surface drainage (depicted in the table in bold characters) is the focus of each example. While the influence of cross and longitudinal slope is examined in Example 1, the influence of different assumed rainfall intensities with a duration of 15 minutes is presented in Example 2. In Example 3, the water depth accumulation during one rainfall event is analyzed, and the drainage conditions over the time span of rut formation (30 years) are examined in Example 4. Finally, the influence of texture depth on the drainage capacity is illustrated in Example 5. Since this parameter is strongly coupled with the cross and longitudinal slopes of the pavement, the influence of these parameters is also studied.

The simulation results show a $2 \mathrm{D}$ distribution of water film depths (WFD) in different colors plotted over the pavement surface. The overall water depth is related to the texture depth (MTD), so the resulting water depth given in 


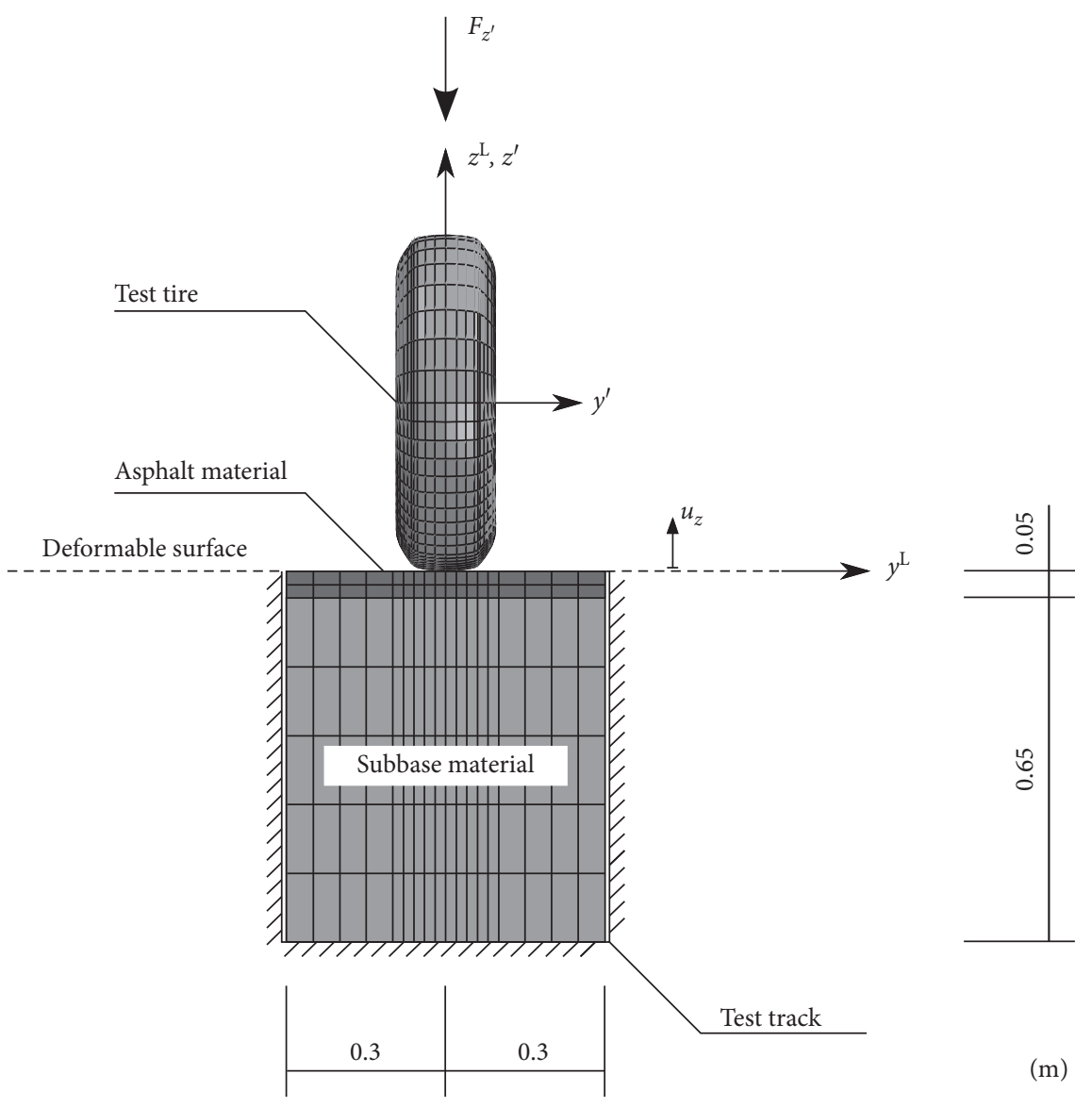

FIGURE 5: Geometry and FE discretization of the benchmark example (cross section of the near field: thin asphalt layer on subbase material of the test track, both with elastoplastic material behavior) and FE model of the test tire [27].

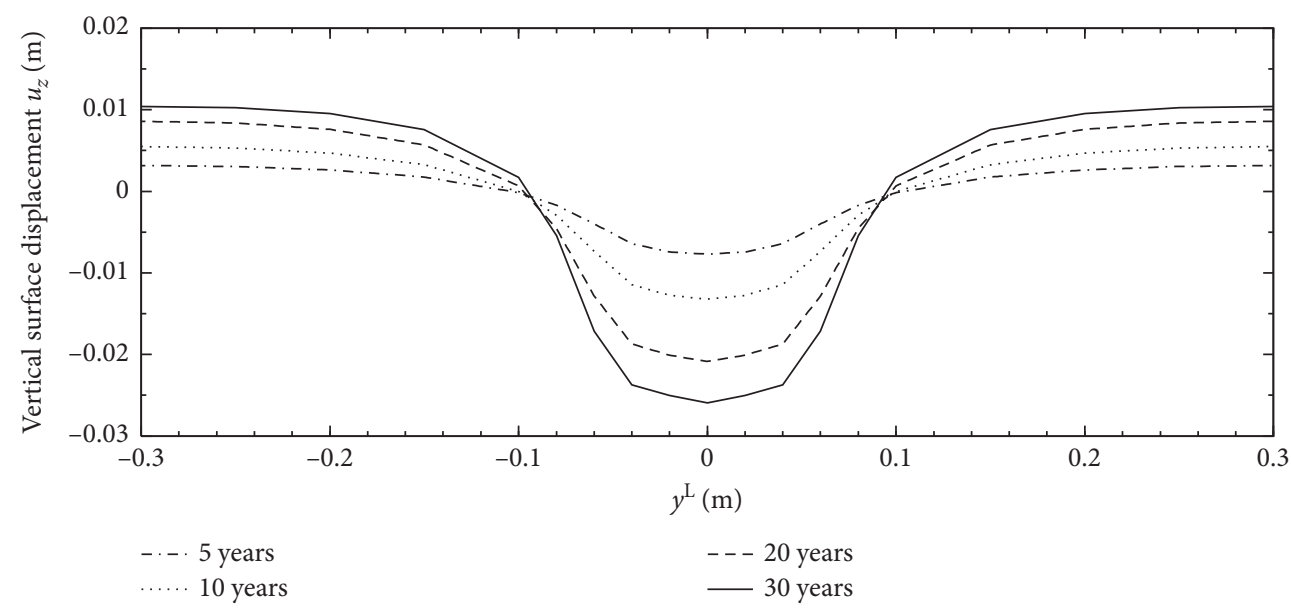

FiguRE 6: Deformed surface of the test track (cross-sectional direction) plotted for a global time of 5 years, 10 years, 20 years, and 30 years (number of load cycles $=$ about $7 \cdot 10^{7}$ per year) [27].

the figures represents the water height above the texture peaks, which is assumed to be relevant to aquaplaning aspects.

Example 1. Effects of cross slope and longitudinal slope in combination with rut depth
Rain intensity of $0.75 \mathrm{~mm} / \mathrm{min}$ with a duration of $15 \mathrm{~min}$ and an MTD value of $0.4 \mathrm{~mm}$ were chosen for the simulation. The cross slope $c$ was chosen as $2.5 \%$ and $5.0 \%$, whereas the longitudinal slope $s$ was chosen as $1.0 \%$ and $4.0 \%$. The geometry of the ruts is taken from the outcome of 


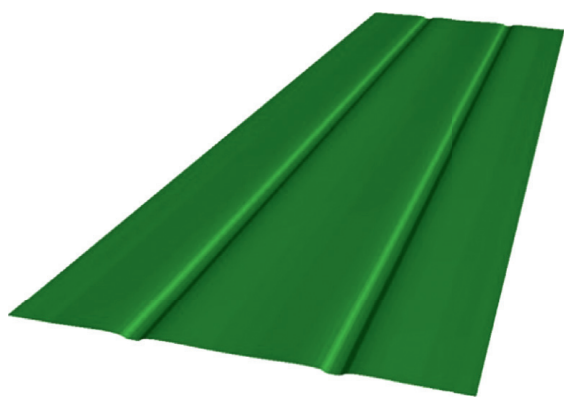

(a)

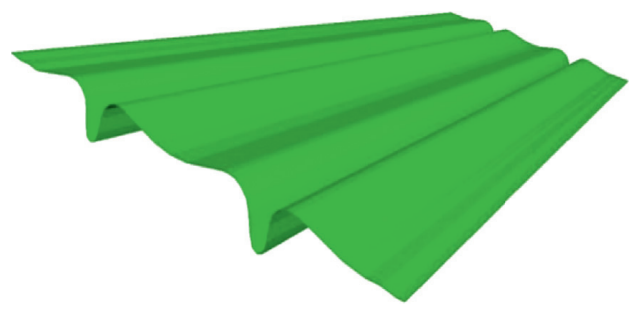

(b)

Figure 7: Generated deformed pavement surface. (a) Unscaled. (b) 10x vertically scaled.

TABLE 1: Simulation parameters for numerical examples of surface drainage (influencing quantities highlighted in bold).

\begin{tabular}{lcccccc}
\hline Example & $i(\mathrm{~mm} / \mathrm{min})$ & Duration $(\mathrm{s})$ & MTD $(\mathrm{mm})$ & $c(\%)$ & $s(\%)$ & $n(\mathrm{years})$ \\
\hline 1 & 0.75 & 900 & 900 & 0.4 & $\mathbf{2 . 5}, \mathbf{5 . 0}$ & $\mathbf{1 . 0 , 4 . 0}$ \\
2 & $\mathbf{0 . 7 5 , 2 . 0}$ & $\mathbf{1 0 - 9 0 0}$ & 0.4 & 2.5 & 30 & 1.0 \\
3 & 0.75 & 900 & 0.4 & 2.5 & 2.0 & 30 \\
4 & 0.75 & 900 & $\mathbf{0 . 4}, \mathbf{0 . 9}$ & $\mathbf{2 . 5}, \mathbf{5 . 0}$ & $\mathbf{1 . 0}-\mathbf{4 . 0}$ & $\mathbf{1 - 3 0}$ \\
5 & 0.75 & &
\end{tabular}

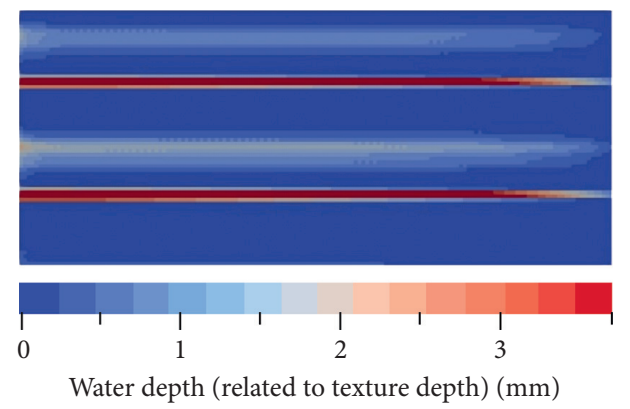

(a)

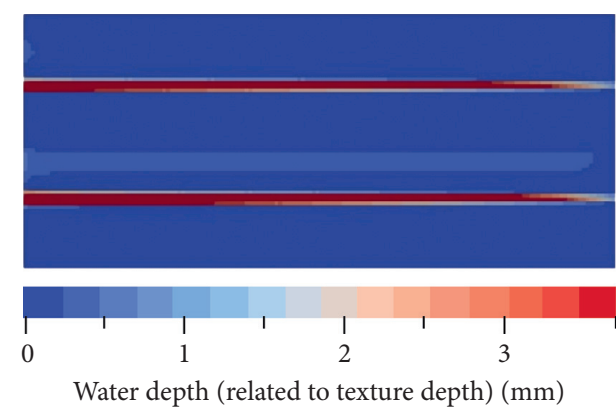

(c)

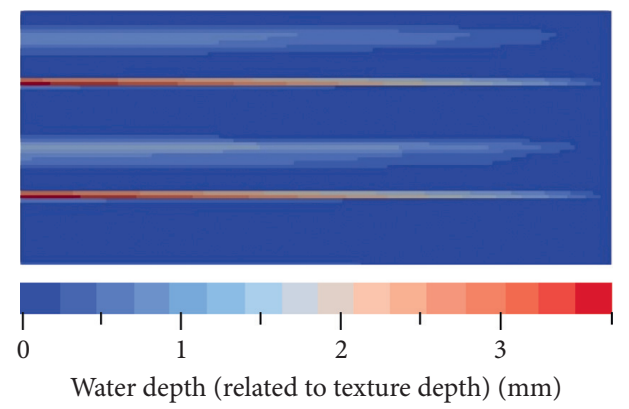

(b)

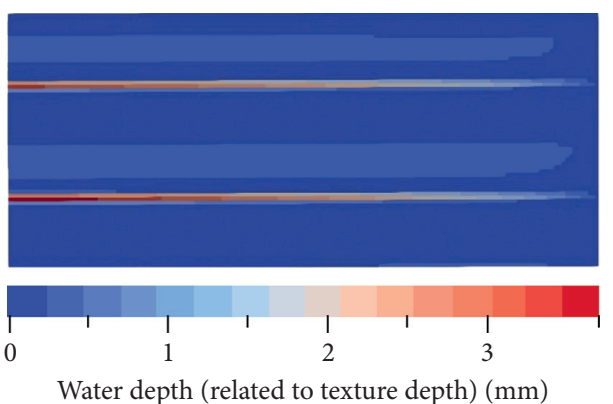

(d)

Figure 8: Example 1: effects of cross slope $c$ and longitudinal slope $s$ on the drainage of a pavement surface with ruts (rut depth and geometry after 30 years). (a) $c=2.5 \%, s=1.0 \%$. (b) $c=2.5 \%, s=4.0 \%$. (c) $c=5.0 \%, s=1.0 \%$. (d) $c=5.0 \%, s=4.0 \%$.

the tire-pavement simulation of a 30-year case. The corresponding rut depth and geometry are depicted in Figure 6.

The results in Figure 8 show, as expected, higher water depths in the ruts than in the surrounding area. The runoff along the ruts is better for longitudinal slopes $s$ with a higher gradient (here: $4.0 \%$ ), leading to lower water depths compared to longitudinal slopes with a lower gradient (here: $1.0 \%)$.

The bulges at the edge of the ruts result in a backwater effect, which occurs next to the (higher edges of the) ruts in all cases. This effect is more significant with cross slopes with a lower gradient, and thus higher water depths appear here. 


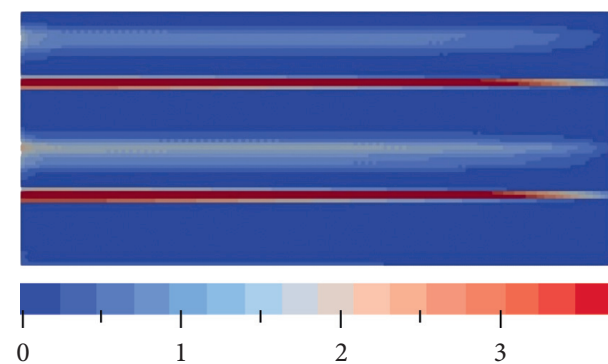

Water depth (related to texture depth) (mm)

(a)

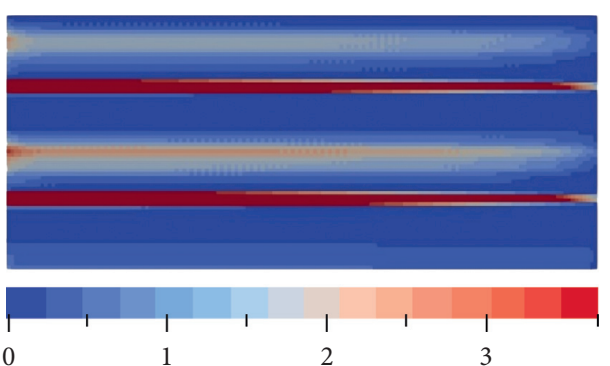

Water depth (related to texture depth) (mm)

(b)

Figure 9: Example 2: effects of different rain intensities $i$ on the drainage of a pavement surface with ruts (rut depth and geometry after 30 years). (a) $i=0.75 \mathrm{~mm} / \mathrm{min}$, duration $15 \mathrm{~min}$. (b) $i=2.0 \mathrm{~mm} / \mathrm{min}$, duration $15 \mathrm{~min}$.
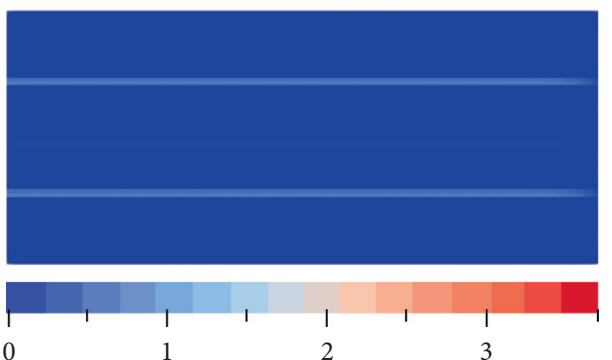

Water depth (related to texture depth) (mm)

(a)
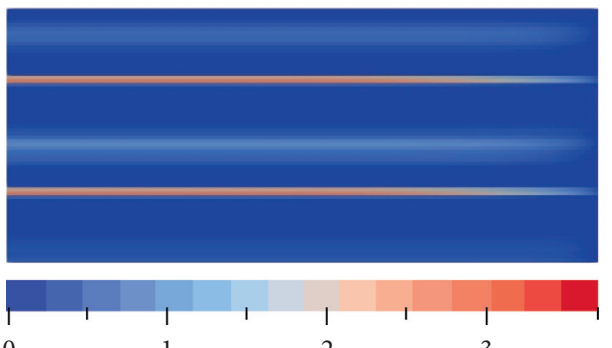

Water depth (related to texture depth) (mm)

(c)

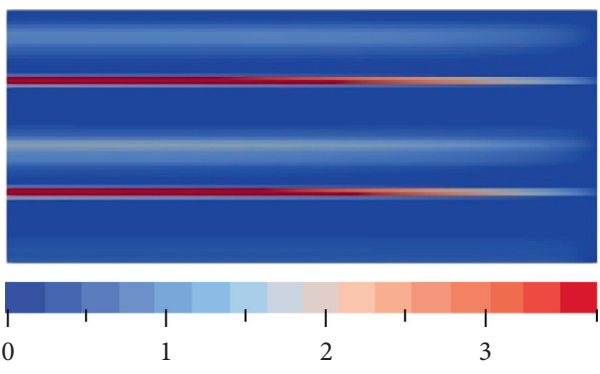

Water depth (related to texture depth) (mm)

(e)

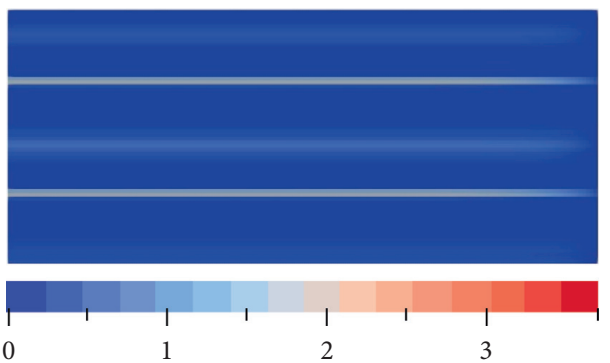

Water depth (related to texture depth) (mm)

(b)

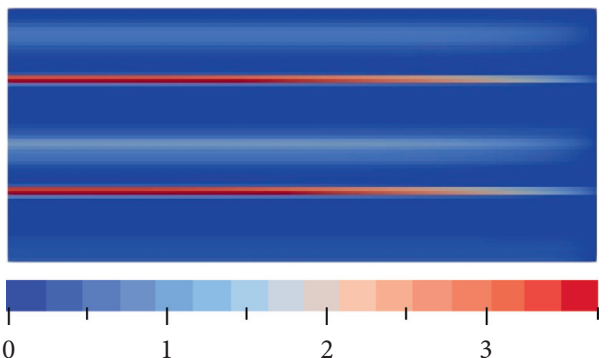

Water depth (related to texture depth) (mm)

(d)

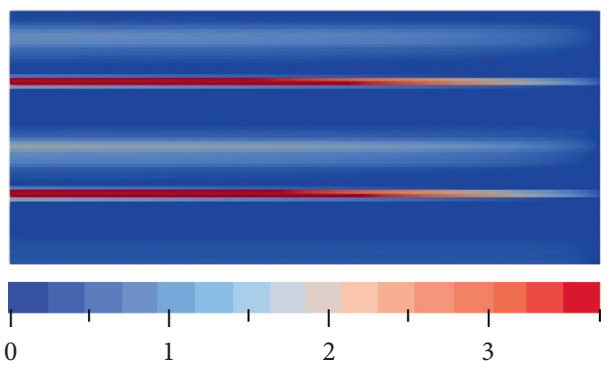

Water depth (related to texture depth) (mm)

(f)

FIgURe 10: Example 3: evolution of water depths in (and outside of) the ruts after the beginning of a heavy rainfall (rut depth and geometry after 30 years). (a) $t=10 \mathrm{~s}$. (b) $t=30 \mathrm{~s}$. (c) $t=45 \mathrm{~s}$. (d) $t=60 \mathrm{~s}$. (e) $t=80 \mathrm{~s}$. (f) $t=900 \mathrm{~s}(15 \mathrm{~min})$. 


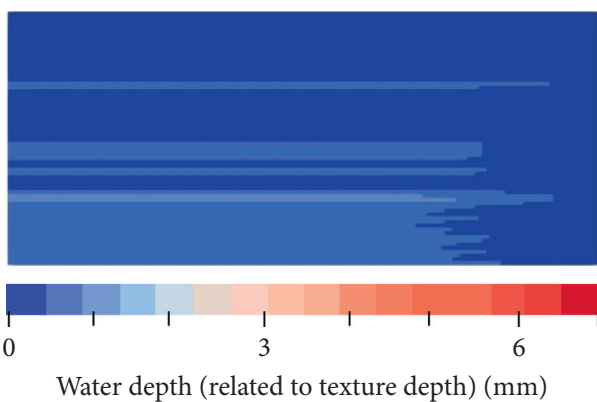

(a)

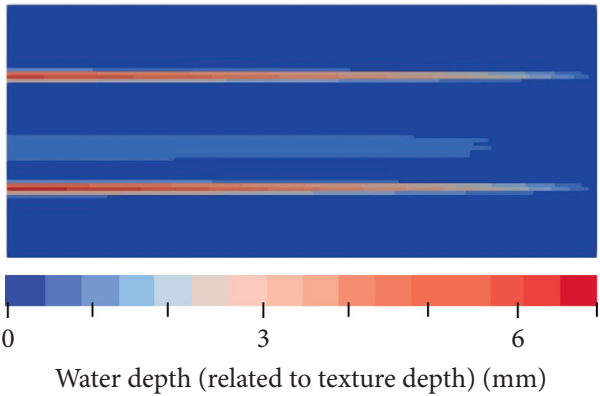

(c)

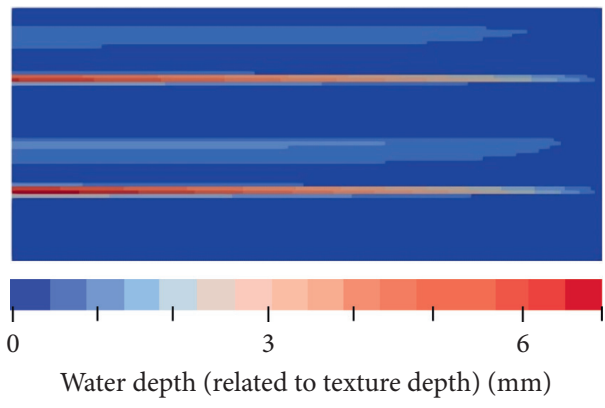

(e)

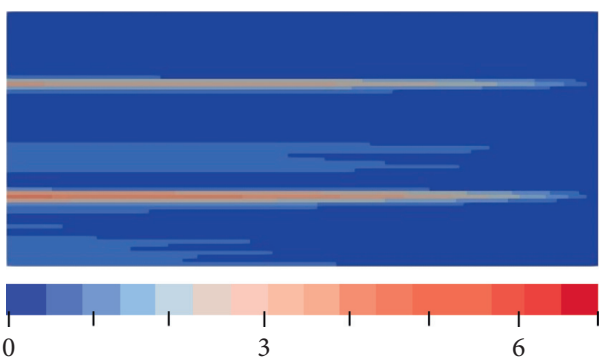

Water depth (related to texture depth) (mm)

(b)

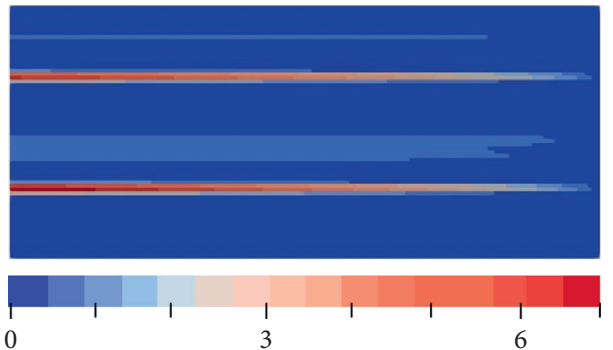

Water depth (related to texture depth) (mm)

(d)

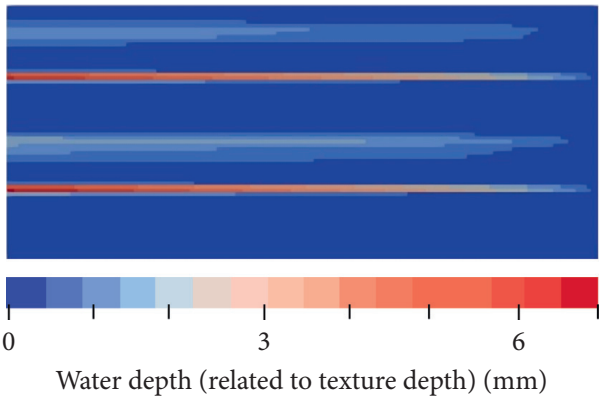

(f)

FIGURE 11: Example 4: effects of increasing rutting on the drainage of a pavement surface. (a) $t=1$ year. (b) $t=5$ years. (c) $t=10$ years. (d) $t=15$ years. (e) $t=20$ years. (f) $t=30$ years.

The effect of the longitudinal slopes on the backwater effect is ambiguous. The area of increased water depths is smaller with a cross slope of $c=2.5 \%$. For the cross slope of $c=5.0 \%$, the area of increased water depths increases with steeper longitudinal slopes, which might be an effect of longer flow paths while the values of water depths themselves are smaller compared to $c=2.5 \%$.

Example 2. Comparison of different rain intensities

For this example, rain intensity is set to $0.75 \mathrm{~mm} / \mathrm{min}$ and $2.0 \mathrm{~mm} / \mathrm{min}$, respectively, with a duration of $15 \mathrm{~min}$ in each case. An MTD value of $0.4 \mathrm{~mm}$ was chosen. The cross slope $c$ is $2.5 \%$ and the longitudinal slope $s$ is $1.0 \%$. The geometry of the ruts is taken from the outcome of the tirepavement simulation of a 30-year case (see Figure 6).

In Figure 9, it can be seen that higher rain intensities lead to an increase of water depths in the ruts as well as in the area next to the bulges at the edges of the ruts (backwater effects). This seems to be an obvious result, but the effects can be quantified in relation to several other input parameters using the method described in this paper.

Example 3. Water depths during heavy rainfall

The time required to reach a critical depth of water in the ruts in the case of a heavy rainfall is investigated in this example. As in Example 2, only the influence of the rainfall properties is the focus. However, in this example, not the rain intensity, but the rain duration is analyzed.

The simulations are based on a rain intensity of $0.75 \mathrm{~mm} /$ min with a duration of $15 \mathrm{~min}$, an MTD value of $0.4 \mathrm{~mm}$, a cross slope of $c=2.5 \%$, a longitudinal slope of $2.0 \%$, and the calculated rut geometry over 30 years.

Critical states regarding aquaplaning tend to be reached earlier within the ruts than outside of the ruts. With the help of calculations, as shown in Figure 10, the discrete time at which a critical value occurs can be estimated. Figure 10 also shows that high values of water depth are reached in the ruts after a relatively short time. After approximately $80 \mathrm{~s}$ of rainfall, a 

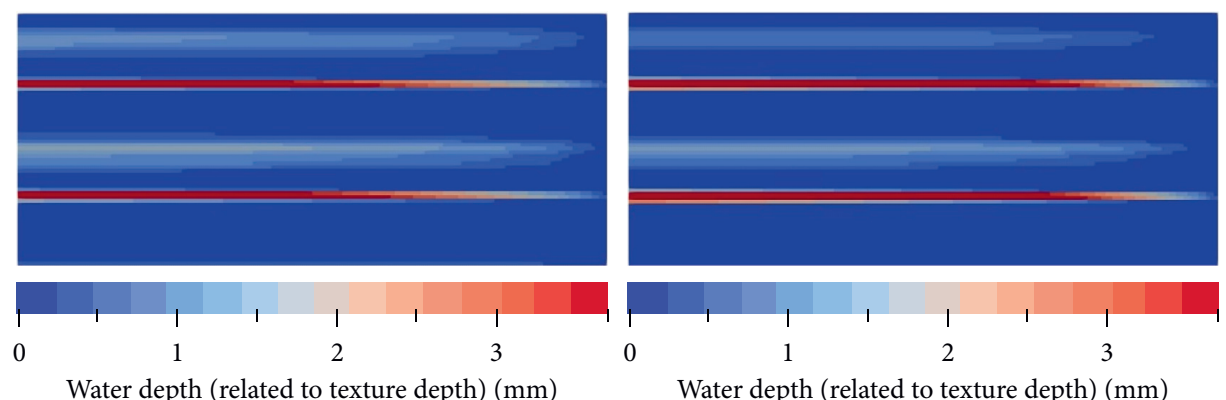

Water depth (related to texture depth) $(\mathrm{mm})$

$c=2.5 \%, S=2.0 \%$
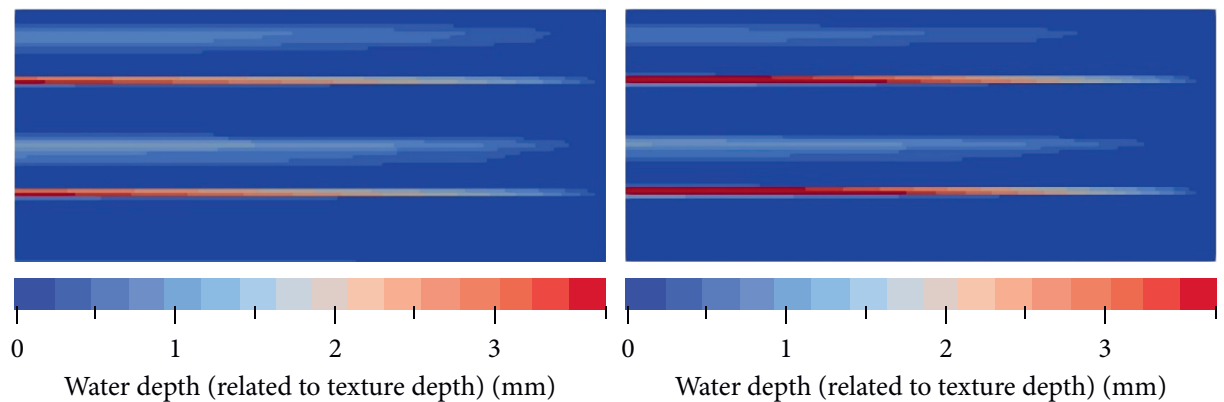

$c=2.5 \%, S=4.0 \%$
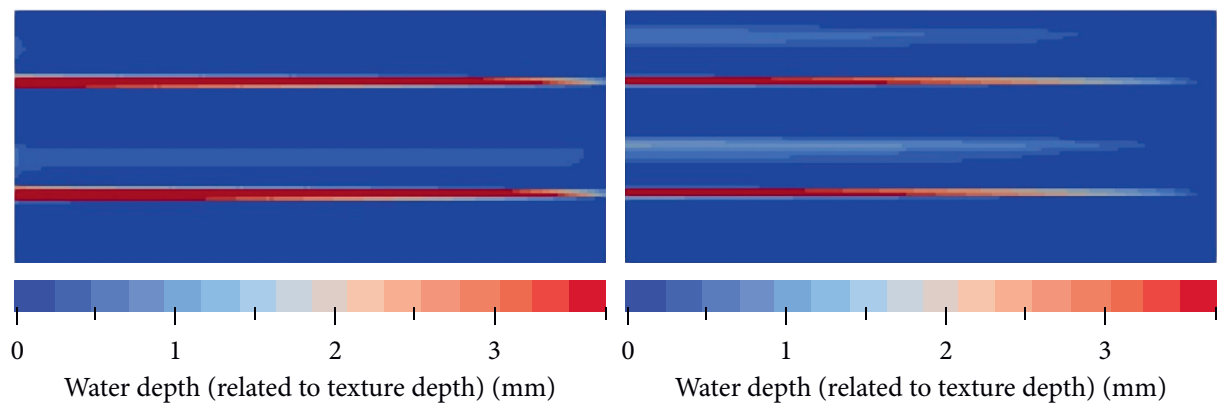

$c=5.0 \%, S=1.0 \%$

Figure 12: Example 5: effect of texture roughness (MTD) on the drainage of a pavement surface with ruts (rut depth and geometry after 30 years). Left: MTD $=0.4 \mathrm{~mm}$; right: $\mathrm{MTD}=0.9 \mathrm{~mm}$.

nearly steady-state condition is reached, i.e., the water depth values in the ruts do not change over time. Therefore, the duration of a rain event does not seem to be such an influencing factor as the rain intensity (see Example 2).

It can also be seen that critical values of water depth seem to appear in the ruts earlier than outside the ruts.

Example 4. Development of drainage with increasing rutting during the pavement's service life

In this example, simulations have been carried out for a rain intensity of $0.75 \mathrm{~mm} / \mathrm{min}$ with a duration of $15 \mathrm{~min}$, an MTD value of $0.4 \mathrm{~mm}, c=2.5 \%$, and $s=2.0 \%$.

In Figure 11, the development of ruts and the drainage effects are shown for different periods of time. The increase of rutting and the decreasing drainage properties can be observed exemplarily. The related rut geometries and rut depth values are given in Figure 6. Within the ruts, the water depths increase significantly in comparison to the surrounding area.

Example 5. Effects of texture on the drainage of a pavement surface with ruts
In this example, the calculations are carried out with a rain intensity of $0.75 \mathrm{~mm} / \mathrm{min}$ with a duration of $15 \mathrm{~min}$. Two MTD values with different cross slopes $c$ in combination with different longitudinal slopes $s$ are investigated. The calculated rut geometry after 30 years is considered.

Different roughness properties of pavement surfaces-numerically expressed via the MTD-have a significant effect on surface drainage. In general, higher MTD values offer a certain water drainage capability in texture cavities, but also increase the flow resistance. Both effects coexist, but one of them can be predominant in different geometric situations (e.g., depending on the slope or flow path length) and, in consequence, can have a major influence on water depth. This contradictory influence of surface roughness on pavement drainage has not yet been sufficiently discussed either qualitatively or quantitatively.

These different (contradictory) effects can be seen in the results depicted in Figure 12. Water depth values are influenced by different texture roughness values in the ruts as well as in the area next to the ruts (backwater area next to 
the bulges) in an ambiguous way. An interesting question in this context could be how the deformation and the macrotexture change in the ruts and how drainage and the resulting water depths are influenced.

\section{Conclusions}

This paper presents a modular hydromechanical approach to assess the short- and long-term surface drainage behavior of arbitrary, deformable asphalt pavements.

Firstly, the results of the laboratory tests of the materials used in the pavement provide information about the material's mechanical short- and long-term characteristics at different temperatures.

Secondly, an FE model dealing with tire-pavement interaction is used to predict the long-term permanent deformation performance of arbitrary asphalt pavements on the structural scale. The model assumes steady-state rolling conditions in order to carry out computationally efficient analyses. In addition, the efficiency is increased by computing the long-term structural response using a time homogenization technique. Based on material parameters from experimental material characterization tests, the structural model provides rut depths and the rut geometry for arbitrary tire-pavement configurations as a function of the number of load cycles.

Thirdly, the results of the long-term pavement modeling (rut depths and rut geometry as a function of the load cycles) are used in a unidirectional coupling to predict the surface drainage behavior of the rutted pavement surface, especially the water depth within the ruts. The basic hydromechanical modeling is based on depth-averaged shallow water equations. This modeling technique can consider ruts (and uneven areas in general) in a pavement because of its $2 \mathrm{D}$ runoff simulation. Modeling water runoff instead of using the rut depth as a benchmark for the risk of aquaplaning offers an additional benefit. Important pavement design and surface parameters can be included in the surface drainage model, e.g., cross slope, longitudinal slope, or even transition areas, which have a major influence on the surface drainage behavior. It can be shown that the surface texture (represented by MTD values) also affects the runoff behavior and the resulting water depths. Varying these parameters enables the pavement's drainage performance and related aquaplaning risks to be assessed. Thus, a prediction of the functional property of surface drainage as well as its implications on road safety could be improved by the present modular coupling, which delivers more precise results by including information about material and simulated surface geometries as a function of the pavement's service life.

Regarding this interdisciplinary hydromechanical modular approach, it is obvious that the combination and coupling of experimental and numerical methods (material, structure, and drainage) can fundamentally improve prediction methods for the long-term, multiphysical behavior of asphalt pavements and their performance. Future research work will concentrate on systematic parameter analyses using the hydromechanical modular approach for application-oriented studies regarding varying material characteristics, existing pavement construction types as well as varying traffic, wheel loads, pavement slopes, etc.

\section{Data Availability}

Parts of the raw data supporting the modular analysis are from previously reported studies and datasets, which have been cited in the text. The processed drainage data are available from the corresponding author upon request.

\section{Conflicts of Interest}

The authors declare that there are no conflicts of interest regarding the publication of this paper.

\section{Acknowledgments}

The authors gratefully acknowledge the financial support by the Deutsche Forschungsgemeinschaft (DFG) under Grants KA 1163/30, RE 1620/4, WE 1642/11, and LE 3649/2 within the DFG Research Group FOR 2089.

\section{References}

[1] G. Wang, R. Roque, and D. Morian, "Effects of surface rutting on near-surface pavement responses based on a two-dimensional axle-tire-pavement interaction finite-element model," Journal of Materials in Civil Engineering, vol. 24, no. 11, pp. 1388-1395, 2012.

[2] I. Wollny, F. Hartung, and M. Kaliske, "Numerical modeling of inelastic structures at loading of steady state rolling-thermo-mechanical asphalt pavement computation," Computational Mechanics, vol. 57, no. 5, pp. 867-886, 2016.

[3] E. R. Brown, P. S. Kandhal, and J. Zhang, "Performance testing for hot mix asphalt," NCAT Report No. 01-05, National Center for Asphalt Technology, Auburn, AL, USA, 2001.

[4] A. Zeißler, F. Wellner, I. Wollny, C. Zopf, and M. Kaliske, "Experimental testing and investigation of the stress-dependent material behaviours of aspahlt via the triaxial test," in Proceedings of the PIARC XXIVth World Road Congress Conference, Mexico City, Mexico, September 2011.

[5] Y.-C. Suh and N.-H. Cho, "Development of a rutting performance model for asphalt concrete pavement based on test road and accelerated pavement test data," KSCE Journal of Civil Engineering, vol. 18, no. 1, pp. 165-171, 2014.

[6] S. Erlingsson, "Modelling of rutting development in pavement structures," Procedia-Social and Behavioral Sciences, vol. 48, pp. 321-330, 2012.

[7] P. Tian, A. Shukla, L. Nie, G. Zhan, and S. Liu, "Characteristics' relation model of asphalt pavement performance based on factor analysis," International Journal of Pavement Research and Technology, vol. 11, no. 1, pp. 1-12, 2018.

[8] M. Shojaeifard, M. Baghani, and H. Shahsavari, "Rutting investigation of asphalt pavement subjected to moving cyclic loads: an implicit viscoelastic-viscoplastic-viscodamage FE framework," International Journal of Pavement Engineering, pp. 1-15, 2018.

[9] B. Ali, M. Sadek, and I. Shahrour, "Finite-element model for urban pavement rutting: analysis of pavement rehabilitation methods," Journal of Transportation Engineering, vol. 135, no. 4, pp. 235-239, 2009. 
[10] O. O. R. Famiyesin, T. G. Davies, and A. H. C. Chan, "Numerical modelling of cyclic loading on reinforced unbound pavements," Computers \& Structures, vol. 68, no. 1-3, pp. 231-249, 1998.

[11] B. Feyissa, "Analysis and modeling of rutting for long life asphaltconcrete pavement," Ph.D. thesis, Technische Universität Darmstadt, Darmstadt, Germany, 2009.

[12] P. Kettil, B. Lenhof, K. Runesson, and N.-E. Wiberg, "Simulation of inelastic deformation in road structures due to cyclic mechanical and thermal loads," Computers \& Structures, vol. 85, no. 1-2, pp. 59-70, 2007.

[13] B. M. Gallaway, D. L. Ivey, G. Hayes et al., Pavement and geometric design criteria for minimizing hydroplaning, Texas Transportation Institute, Texas A\&M University, College Station, TX, USA, 1979.

[14] D. A. Anderson, R. S. Huebner, J. R. Reed, J. C. Warner, and J. J. Henry, "Improved surface drainage of pavements-Final report," Pennsylvania Transportation Institute, Wingate, PA, USA, 1998.

[15] C. M. Cristina and J. J. Sansalone, "Kinematic wave model of urban pavement rainfall-runoff subject to traffic loadings," Journal of Environmental Engineering, vol. 129, no. 7, pp. 629-636, 2003.

[16] S. Hermann, "Simulationsmodell zum Wasserabfluss- und Aquaplaning-Verhalten auf Fahrbahnoberflächen," Ph.D. thesis, Universität Stuttgart, Stuttgart, Germany, 2008.

[17] R. J. Charbeneau, J. Jeong, and M. E. Barrett, "Highway drainage at superelevation transitions," Center for Transportation Research, University of Texas at Austin, Austin, TX, USA, 2008.

[18] I. Wollny and M. Kaliske, "Numerical simulation of pavement structures with inelastic material behaviour under rolling tyres based on an arbitrary Lagrangian Eulerian (ALE) formulation," Road Materials and Pavement Design, vol. 14, no. 1, pp. 71-89, 2013.

[19] M. Oeser, "Nichtlineare numerische Simulationsmodelle für Verkehrswegebefestigungen unter Berücksichtigung von mechanischen, thermischen und hydraulischen Einwirkungen,” Technische Universität Dresden, Dresden, Germany, Habilitationsschrift, 2010.

[20] M. Oeser and T. Pellinien, "Computational framework for common visco-elastic models in engineering based on the theory of rheology," Computers and Geotechnics, vol. 42, pp. 145-156, 2012.

[21] A. Zbiciak, "Mathematical description of rheological properties of asphalt-aggregate mixes," Bulletin of the Polish Academy of Sciences: Technical Sciences, vol. 61, no. 1, pp. 65-72, 2013.

[22] T. Blume, "Mikromechanisch begründete Modellbildung des thermoechanischen Werkstoffverhaltens von Asphalt," Ph.D. thesis, Technische Universität Braunschweig, Braunschweig, Germany, 2018.

[23] C. Netzker, H. Dal, and M. Kaliske, "An endochronic plasticity formulation for filled rubber," International Journal of Solids and Structures, vol. 47, no. 18-19, pp. 2371-2379, 2010.

[24] C. Zopf, M. A. Garcia, and M. Kaliske, "A continuum mechanical approach to model asphalt," International Journal of Pavement Engineering, vol. 16, no. 2, pp. 105-124, 2015.

[25] M. Oeser, Numerische Simulation des nichtlinearen Verhaltens flexibler mehrschichtiger Verkehrswegebefestigungen, Ph.D. thesis, Technische Universität Dresden, Dresden, Germany, 2004.

[26] P. Liu, D. Wang, F. Otto, J. Hu, and M. Oeser, "Application of semi-analytical finite element method to evaluate asphalt pavement bearing capacity," International Journal of Pavement Engineering, vol. 19, no. 6, pp. 479-488, 2018.
[27] R. Behnke, I. Wollny, F. Hartung, and M. Kaliske, "Thermomechanical finite element prediction of the structural longterm response of asphalt pavements subjected to periodic traffic load: tire-pavement interaction and rutting," Computers \& Structures, vol. 218, pp. 9-31, 2019.

[28] M. Bhattacharyya, A. Fau, U. Nackenhorst, D. Néron, and P. Ladevèze, "A multi-temporal scale model reduction approach for the computation of fatigue damage," Computer Methods in Applied Mechanics and Engineering, vol. 340, pp. 630-656, 2018.

[29] T. Guennouni, "Sur une méthode de calcul de structures soumises à des chargements cycliques: l'homogénéisation en temps," ESAIM: Mathematical Modelling and Numerical Analysis, vol. 22, no. 3, pp. 417-455, 1988.

[30] S. Haouala, "Time and space (4D) homogenization for viscoelastic-viscoplastic solids under large numbers of cycles," Ph.D. thesis, Catholic University of Leuven, Leuven, Belgium, 2016.

[31] C. Oskay and J. Fish, "Fatigue life prediction using 2-scale temporal asymptotic homogenization," International Journal for Numerical Methods in Engineering, vol. 61, no. 3, pp. 329-354, 2004.

[32] Q. Yu and J. Fish, "Temporal homogenization of viscoelastic and viscoplastic solids subjected to locally periodic loading," Computational Mechanics, vol. 29, no. 3, pp. 199-211, 2002.

[33] D. Cojocaru and A. Karlsson, "A simple numerical method of cycle jumps for cyclically loaded structures," International Journal of Fatigue, vol. 28, no. 12, pp. 1677-1689, 2006.

[34] R. Behnke and M. Kaliske, "Finite element based analysis of reinforcing cords in rolling tires: influence of mechanical and thermal cord properties on tire response," Tire Science and Technology, vol. 46, no. 4, pp. 294-327, 2018.

[35] C. F. Izzard, "The surface-profile of overland-flow," Transactions, American Geophysical Union, vol. 25, no. 6, pp. 959-968, 1944.

[36] D. C. Woo and E. F. Brater, "Spatially varied flow from controlled rainfall," Journal of the Hydraulics Division: HY Proceedings of the American Society of Civil Engineers, vol. 88, pp. 31-56, 1962.

[37] N. F. Ross and K. Russam, "The depth of rain water on road surfaces," Road Research Laboratory, RRL Report LR 236, Ministry of Transport, Crowthorne, England, UK, 1968.

[38] H. J. Höcker, "Die Oberflächenentwässerung von Fahrbahnen und ihre Bedeutung für den Straßenentwurf," in Forschung Straßenbau und Straßenverkehrstechnik, Vol. 118, Wirtschaftsverlag NW, Bonn, Germany, 1971.

[39] B. M. Gallaway, J. G. Rose, and R. E. Schiller Jr., "The relative effects of several factors affecting rainwater depths on pavement surfaces," Highway Research Record, vol. 396, pp. 59-71, 1972.

[40] R. S. Huebner, D. A. Anderson, J. C. Warner, and J. R. Reed, "PAVDRN: computer model for predicting water film thickness and potential for hydroplaning on new and reconditioned pavements," Transportation Research Record: Journal of the Transportation Research Board, vol. 1599, no. 1, pp. 128-131, 1997.

[41] W. Ressel and S. Hermann, "Aquaplaning und Verkehrssicherheit in Verwindungsbereichen dreistreifiger Richtungsfahrbahnen-Berechnung der Wasserfilmdicke," in Forschung Straßenbau und Straßenverkehrstechnik, Vol. 997, Wirtschaftsverlag NW, Bonn, Germany, 2008.

[42] A. Wolff, "Simulation of pavement surface runoff using the depth-averaged shallow water equations," Ph.D. thesis, Universität Stuttgart, Stuttgart, Germany, 2013. 
[43] V. Ranieri, "Runoff control in porous pavements," Transportation Research Record: Journal of the Transportation Research Board, vol. 1789, no. 1, pp. 46-55, 2002.

[44] B. J. Eck, M. E. Barrett, and R. J. Charbeneau, "Coupled surface-subsurface model for simulating drainage from permeable friction course highways," Journal of Hydraulic Engineering, vol. 138, no. 1, pp. 13-22, 2012.

[45] M. Kaliske, I. Wollny, R. Behnke, and C. Zopf, "Holistic analysis of the coupled vehicle-tire-pavement system for the design of durable pavements," Tire Science and Technology, vol. 43, pp. 86-116, 2015.

[46] W. Ressel and I. Rucker, "A numerical drainage model to simulate infiltration into porous pavements for higher road safety," Internationales Stuttgarter Symposium Automobilund Motorentechnik, pp. 455-465, Springer Vieweg, Wiesbaden, Germany, 2017.

[47] W. Ressel, A. Wolff, S. Alber, and I. Rucker, "Modelling and simulation of pavement drainage," International Journal of Pavement Engineering, vol. 20, no. 7, pp. 801-810, 2019.

[48] B. Flemisch, J. Fritz, R. Helmig, J. Niessner, and B. Wohlmuth, "DuMuX: A multi-scale multi-physics toolbox for flow and transport processes in porous media," in Proceedings of the ECCOMAS Conference 2007, pp. 82-87, Paris, France, September 2007.

[49] B. Flemisch, M. Darcis, K. Erbertseder et al., "DuMux: DUNE for multi-\{phase, component, scale, physics, ... flow and transport in porous media," Advances in Water Resources, vol. 34, no. 9, pp. 1102-1112, 2011.

[50] P. Bastian, M. Blatt, A. Dedner et al., "A generic grid interface for parallel and adaptive scientific computing. Part I: abstract framework," Computing, vol. 82, no. 2-3, pp. 103-119, 2008.

[51] P. Bastian, M. Blatt, A. Dedner et al., "A generic grid interface for parallel and adaptive scientific computing. Part II: implementation and tests in DUNE," Computing, vol. 82, no. 2-3, pp. 121-138, 2008.

[52] S. A. Tan, T. F. Fwa, and K. C. Chai, "Drainage considerations for porous asphalt surface course design," Transportation Research Record: Journal of the Transportation Research Board, vol. 1868, no. 1, pp. 142-149, 2004.

[53] G. Malitz and H. Ertel, "KOSTRA-DWD-2010 Starkniederschlagshöhen für Deutschland (Bezugszeitraum 1951 bis 2010)," Deutscher Wetterdienst, Offenbach, Germany, Abschlussbericht, 2015. 